\title{
Budi daya Terapung Tanaman Sawi Hijau dengan Perbedaan Dosis Pupuk NPK, Ukuran Polibag, dan Waktu Pemupukan
}

\section{(Floating cultivation of mustards green on different NPK Doses, Polybag Sizes, and Fertilizing Times)}

\author{
Erna Siaga $^{1 *}$, Benyamin Lakitan ${ }^{2}$ \\ (Diterima September 2020/Disetujui Januari 2021)
}

\begin{abstract}
ABSTRAK
Budi daya sayuran sawi hijau terapung merupakan salah satu cara budi daya tanaman alternatif yang dapat dilakukan pada saat periode banjir di lahan rawa lebak pada musim penghujan. Pemanfaatan lahan banjir untuk praktik budi daya sayuran dapat meningkatkan indeks pertanaman sekaligus menambah pendapatan petani rawa lebak. Tujuan penelitian ini ialah untuk mengevaluasi pertumbuhan dan hasil tanaman sawi hijau pada budi daya terapung dengan aplikasi perbedaan dosis pupuk NPK, ukuran polibag, dan waktu pemupukan sehingga diperoleh praktik budi daya sawi hijau terapung yang efektif dan efisien. Penelitian ini dilaksanakan pada bulan Oktober 2016Februari 2017 di Fasilitas Penelitian Jakabaring (104 46'44"E; $3^{\circ} 01^{\prime} 35^{\prime \prime}$ 'S) dan Laboratorium Kimia Hasil Pertanian (LKHP), Fakultas Pertanian, Universitas Sriwijaya, Palembang. Penelitian ini terdiri atas dua tahapan percobaan. Percobaan pertama menggunakan Rancangan Acak Lengkap (RAL) dengan perlakuan 4 (empat) dosis pupuk NPK (16:16:16), yaitu 0 (kontrol), 5, 10, dan $15 \mathrm{~g}_{\text {tanaman }}{ }^{-1}$. Percobaan kedua menggunakan Rancangan Petak Terbagi (Split Plot) dengan 2 (dua) faktor, yaitu ukuran polibag dan waktu pemupukan. Percobaan pertama menunjukkan hasil bahwa ketiga dosis pemupukan memberikan hasil yang berbeda nyata pada panjang tajuk, jumlah daun, dan bobot segar panen dibandingkan dengan kontrol. Percobaan kedua menunjukkan hasil bahwa perbedaan ukuran polibag (A1 dan A2) dan waktu pemupukan ( $F 1, F 2$, dan $F 3$ ) tidak berpengaruh nyata pada beberapa parameter pertumbuhan dan hasil. Pemakaian dosis pupuk NPK $5 \mathrm{~g}$ tanaman ${ }^{-1}$ pada saat 1 Minggu Setelah Tanam (MST) dengan menggunakan polibag $30 \times 30 \mathrm{~cm}$ dengan komposisi media tanam berupa tanah, pupuk kandang, dan sekam padi (1:1:1/ v:v:v) merupakan praktik budi daya sawi hijau terapung yang efektif dan efisien.
\end{abstract}

Kata kunci: budi daya terapung, pemupukan, NPK, sawi hijau

\section{ABSTRACT}

Cultivation of mustards green on floating raft is one of alternative cultivations which is applied by traditional farmers during flooding period in Riparian Wetland. The cultivation will increase Cropping Index and farmer's income. The objective of this research is to evaluate growth and yield of mustards green on floating cultivation with the application of different NPK doses, polybag sizes, and fertilization times to find cultivation of mustards green which effective and efficient. This research was conducted on October 2016-February 2017 in Jakabaring Facility (10446'44" E; 3`01'35" S) and Kimia Hasil Pertanian (LKHP) Laboratory, Fakultas Pertanian, Universitas Sriwijaya, Palembang. This research consisted of two steps. The first experiment used a completely randomized design with four doses of NPK (16:16:16) namely 0 (control), 5, 10, and $15 \mathrm{~g} \mathrm{plant}^{-1}$. The second experiment used a Split Plot Design consisted of two factors namely polybag size (A1 and A2) and fertilization time (F1, F2, and F3). The result of the first experiment showed that utilization three doses of NPK significantly increased shoot length, number of leaves, and fresh weight compared control. The second experiment showed that polybag size and fertilization time did not significantly affect growth and yield parameters. Utilization of $5 \mathrm{~g} \mathrm{plant}^{-1}$ of NPK on 1 week after transplanting (WAT) which used polybag size of $30 \times 30 \mathrm{~cm}$ on growing media consisted of soil, manure, and rice husk (1:1:1/v:v:v) produced an effective and efficient cultivation of mustards green.

Keywords: fertilizing, floating cultivation, green mustard, NPK

\section{PENDAHULUAN}

Indonesia memiliki luas lahan rawa lebak yang sangat luas. Akan tetapi, sebagian besar lahan lebak

1 Program Studi Agroteknologi, Fakultas Pertanian, Universitas Bina Insan, Jl. Jendral Besar Moh. Soeharto KM. 13 Kota Lubuk Linggau 31626

2 Program Studi Agronomi, Fakultas Pertanian, Universitas Sriwijaya, Jl. Palembang-Prabumulih KM. 32, Indralaya 30662

* Penulis Korespondensi:

Email: ernasiaga@univbinainsan.ac.id masih belum termanfaatkan secara maksimal disebabkan oleh banjir lahan pada saat musim hujan yang dapat terjadi hingga enam bulan. Pada periode banjir tersebut, kegiatan budi daya tanaman yang dilakukan oleh petani nyaris tidak ada (Irmawati et al. 2016; Lakitan et al. 2018). Risiko yang tinggi kehilangan tanaman karena banjir menjadi ancaman serius bagi petani kecil pada lahan rawa lebak tersebut. Islam et al. (2015) menyarankan petani kecil di lahan rawa lebak dapat mengadopsi sistem budi daya 
terapung untuk kegiatan bercocok tanam selama periode banjir.

Budi daya sayuran daun terapung merupakan salah satu cara yang dapat diterapkan untuk budi daya tanaman selama periode banjir yang tidak terlalu lama 2-3 bulan di lahan rawa lebak pematang. Salah satu keuntungan budi daya tanaman secara terapung ialah tidak perlunya dilakukan penyiraman karena air dapat berdifusi langsung dan kontinu melalui dasar media tanam. Adapun komoditas sayuran daun yang pernah diproduksi melalui budi daya terapung di antaranya adalah kangkung dengan menggunakan rakit bambu (Bernas et al. 2012), bayam dengan menggunakan limbah plastik (Syafrullah 2014), serta pakcoi dan selada dengan sistem hidroponik (Utomo et al. 2014; Siregar et al. 2015; Marlina et al. 2015). Budi daya sayuran daun pada dasarnya memiliki keuntungan utama, yaitu berupa waktu panen yang cepat sehingga dalam satu periode banjir dapat dilakukan 2-3 kali penanaman.

Sawi hijau atau juga dikenal dengan nama caisin, caisim, atau sawi bakso merupakan salah satu jenis sayuran daun yang tidak sulit pada praktik budi dayanya, terutama pada budi daya terapung (Karya et al. 2015). Sawi hijau tergolong tanaman sayuran daun yang memiliki nilai ekonomi tinggi dan sudah sangat populer di kalangan masyarakat. Pada umumnya, tanaman sawi hijau ditanam di daerah dataran rendah maupun tinggi dan pemanenan dilakukan pada umur 30-60 hari setelah tanam (Daquagrotechno 2018).

Budi daya terapung di lahan rawa lebak dengan konsep media polibag di atas rakit berbeda dari budi daya terapung tanpa media tanam, seperti halnya pada konsep hidroponik, karena air lahan tidak menjadi sumber hara utama. Hal ini menjadikan salah satu faktor penting yang perlu diperhatikan pada sistem budi daya terapung di lahan rawa lebak di antaranya adalah dosis pupuk yang diperlukan, ukuran polibag yang digunakan, dan waktu pemupukan untuk mendapatkan cara budi daya yang efektif dan efisien. Siaga et al. (2018) melaporkan bahwa budi daya terapung dengan media polibag yang diletakkan di atas rakit telah dilakukan pada tanaman cabai dengan hasil panen yang berbeda nyata lebih tinggi dibandingkan dengan budi daya secara konvensional. Difusi air dapat terjadi dengan optimal dengan ketinggian media tanam pada polibag 15-20 cm melalui lubang yang terdapat merata pada dasar polibag.

Sistem budi daya sayuran terapung yang efektif dan efisien sangat diperlukan agar sistem budi daya tersebut mudah diterima dan diadopsi oleh petani rawa lebak sehingga dapat menjadi tanaman budi daya utama pada saat banjir. Oleh karena itu, tujuan penelitian ini ialah untuk mengevaluasi pertumbuhan dan hasil tanaman sawi hijau pada budi daya terapung dengan aplikasi perbedaan dosis pupuk NPK, ukuran polibag, dan waktu pemupukan untuk mendapatkan praktik budi daya sawi hijau terapung yang efektif dan efisien.

\section{METODE PENELITIAN}

Penelitian ini dilaksanakan pada bulan Oktober 2016-Februari 2017 di Fasilitas Penelitian Jakabaring (10446'44"E;301'35" S) dan Laboratorium Kimia Hasil Pertanian (LKHP), Fakultas Pertanian, Universitas Sriwijaya, Palembang.

Bahan yang digunakan berupa benih sawi hijau varietas Tosakan, tanah, pupuk kandang, sekam padi, pupuk NPK, dan insektisida kimia (Fipronil 50g/L). Alat yang digunakan dalam penelitian ini ialah rakit terapung, penggaris, $\mathrm{pH}$ meter, timbangan analitik, polibag, dan tray pembibitan.

Rakit yang digunakan pada budi daya terapung ini ialah rakit berbahan utama botol plastik bekas ukuran $1500 \mathrm{ml}$, yang diikat pada bambu belah, kemudian dikelilingi oleh kerangka pipa PVC 3/4 inch yang disambung tiap sudutnya dengan penyambung pipa 'L', kemudian untuk menyatukan botol-botol plastik dengan bambu belah dan kerangka pipa digunakan tali pancing yang berukuran diameter $1 \mathrm{~mm}$. Rakit ini memiliki dimensi 1,6 m (panjang) x 0,98 $\mathrm{m}$ (lebar) $\mathrm{x}$ 0,078 m (tinggi) (Siaga et al. 2018).

Penelitian ini terdiri atas dua tahap percobaan. Percobaan pertama menggunakan Rancangan Acak Lengkap (RAL) dengan perlakuan 4 (empat) dosis pupuk NPK (16:16:16), yaitu 0 (kontrol), 5, 10, dan 15 $\mathrm{g}$ tanaman $^{-1}$. Masing-masing perlakuan diulang 3 kali dan masing-masing satuan percobaan terdiri atas 9 tanaman. Total tanaman per perlakuan ialah sebanyak 27 tanaman sawi hijau dan total keseluruhan tanaman adalah 108 tanaman sawi hijau. Rakit yang digunakan sebanyak 4 rakit dengan jumlah polibag sebanyak 27 per rakit dengan satu tanaman per polibag. Kontak dasar polibag dan permukaan air diatur agar terdapat kontak langsung sehingga air dapat naik mengisi media tanam dalam polibag (Gambar 1). Komposisi media tanam yang digunakan terdiri atas tanah dan pupuk kandang dengan perbandingan 3:1 (v:v).

Percobaan kedua menggunakan Rancangan Petak Terbagi dengan 2 (dua) faktor, yaitu ukuran polibag $(A)$ sebagai petak utama, yaitu $A 1$ : polibag ukuran $20 \mathrm{~cm} x$ $30 \mathrm{~cm}$; $A 2=$ polibag ukuran $30 \mathrm{~cm} \times 30 \mathrm{~cm}$ dan waktu pemupukan $(F)$ sebagai anak petak, yaitu $F 0=$ tanpa pemupukan; $F 1=5 \mathrm{~g}$ tanaman $^{-1}$ pada 1 minggu setelah

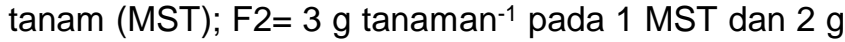
tanaman ${ }^{-1}$ pada 2 MST; F3 $=2 \mathrm{~g}_{\text {tanaman }}^{-1}$ pada 1 dan 2 MST dan $1 \mathrm{~g}$ tanaman $^{-1}$ pada 3 MST. Terdapat 8 kombinasi perlakuan yang masing-masing diulang 3 kali. Masing-masing unit percobaan terdiri atas 5 tanaman. Total tanaman per perlakuan ialah sebanyak 15 tanaman sawi hijau dan total keseluruhan tanaman ialah 120 tanaman sawi hijau. Rakit yang digunakan sebanyak 4 rakit dengan jumlah polibag sebanyak 30 per rakit. Komposisi media tanam yang digunakan adalah tanah, pupuk kandang, dan sekam padi dengan perbandingan 1:1:1 (v:v:v). Media dicampur secara merata dan dimasukkan ke dalam polibag A1 dan A2 dengan banyak media tanaman yang digunakan sama. 
Data yang diperoleh dari hasil pengamatan dan pengukuran dianalisis menggunakan metode Analysis of Variance (ANOVA), jika hasil menunjukkan perbedaan yang nyata maka akan diuji lanjut BNT 5\% dengan bantuan program SAS University Edition.

\section{HASIL DAN PEMBAHASAN}

Pertumbuhan tanaman sawi hijau secara terapung diperoleh melalui pengukuran pada panjang akar, panjang tajuk, dan jumlah daun sawi hijau. Pada percobaan pertama, hasil yang berbeda tidak nyata antara dosis pupuk NPK 0 (kontrol), 5, 10, dan $15 \mathrm{~g}$ tanaman ${ }^{-1}$ terdapat pada nilai panjang akar, namun

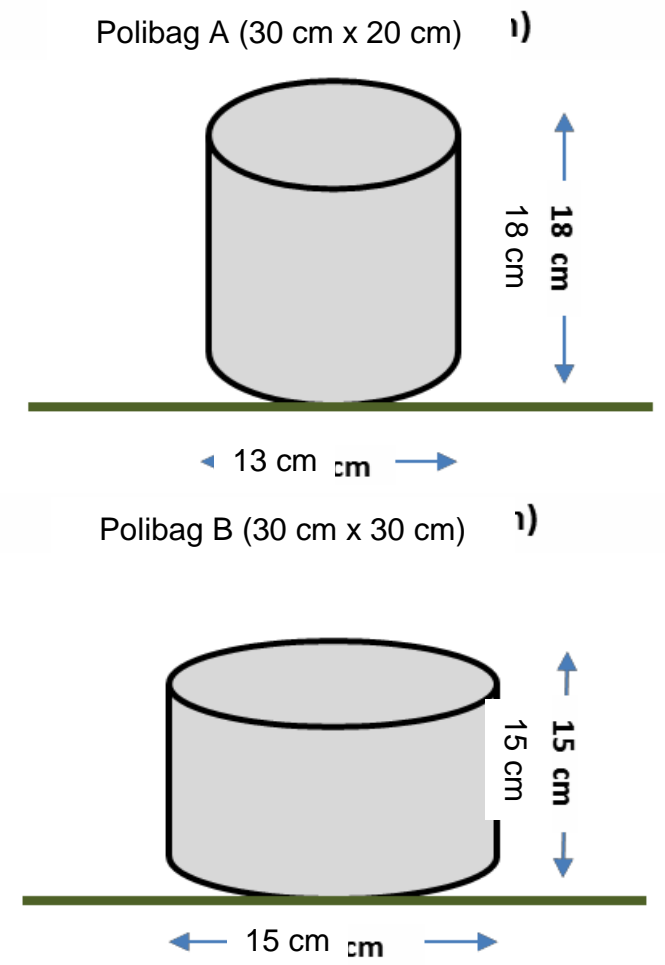

Gambar 1 Dimensi polibag di atas permukaan air/rakit. dosis pupuk NPK 5, 10, dan $15 \mathrm{~g}^{2}$ tanaman ${ }^{-1}$ berbeda nyata dibandingkan dengan dosis pupuk NPK 0 (kontrol) pada panjang tajuk dan jumlah daun (Gambar 2).

Perbedaan nyata juga ditunjukkan antara dosis pupuk NPK $5 \mathrm{~g}$ tanaman $^{-1}$ dengan 10, dan $15 \mathrm{~g}$ tanaman $^{-1}$ pada bobot segar panen (BSP) per tanaman, namun terdapat perbedaan tidak nyata pada hasil bobot kering panen (BKP) per tanaman, sedangkan untuk rasio tajuk akar tidak berbeda nyata antarketiga dosis pupuk NPK maupun kontrol (Gambar 3). Semakin tinggi dosis pupuk NPK yang diberikan akan meningkatkan hasil panen sawi hijau. Hal ini berkorelasi positif dengan nilai SPAD yang juga meningkat seiring dengan peningkatan dosis pupuk NPK. Hasil panen dan nilai SPAD tertinggi diperoleh pada aplikasi pemupukan NPK dengan dosis $15 \mathrm{~g}$ tanaman ${ }^{-1}$. Herve et al. (2017) melaporkan bahwa pada tanaman padi, pemberian pupuk NPK dengan dosis berbeda memberikan hasil yang signifikan berbeda, sedangkan pada tanaman terong, perlakuan dosis NPK berpengaruh sangat nyata pada tinggi tanaman, jumlah daun, jumlah buah, dan bobot basah per tanaman (Hariyadi et al. 2020). Hal berbeda pada tanaman cabai, perlakuan pupuk NPK Mutiara (M) berpengaruh nyata pada tinggi tanaman umur 40 hari, 60 hari setelah tanaman, dan umur pada saat panen, berpengaruh tidak nyata pada tinggi tanaman umur 20 hari setelah tanam, jumlah cabang, umur pada saat berbunga, jumlah buah/tanaman, dan bobot buah/tanaman (Prasetya 2014).

Berdasarkan hasil percobaan pertama yang telah dilakukan, diketahui bahwa dosis pupuk NPK $15 \mathrm{~g}$ tanaman $^{-1}$ memberikan hasil yang berbeda tidak nyata dibandingkan dengan dosis pupuk NPK 5 dan $10 \mathrm{~g} \mathrm{tanaman}^{-1}$ pada karakter morfologi (panjang akar, tajuk, dan jumlah daun), namun mendapatkan hasil BSP tertinggi dibanding kedua dosis pupuk NPK tersebut dengan hasil mendekati $80 \mathrm{~g} \operatorname{tanaman}^{-1}$. Hal ini menunjukkan ketidakefektivan peningkatan dosis pupuk NPK terjadi pada tanaman dalam peranan dalam aktivitas fotosintesis yang juga terlihat pada
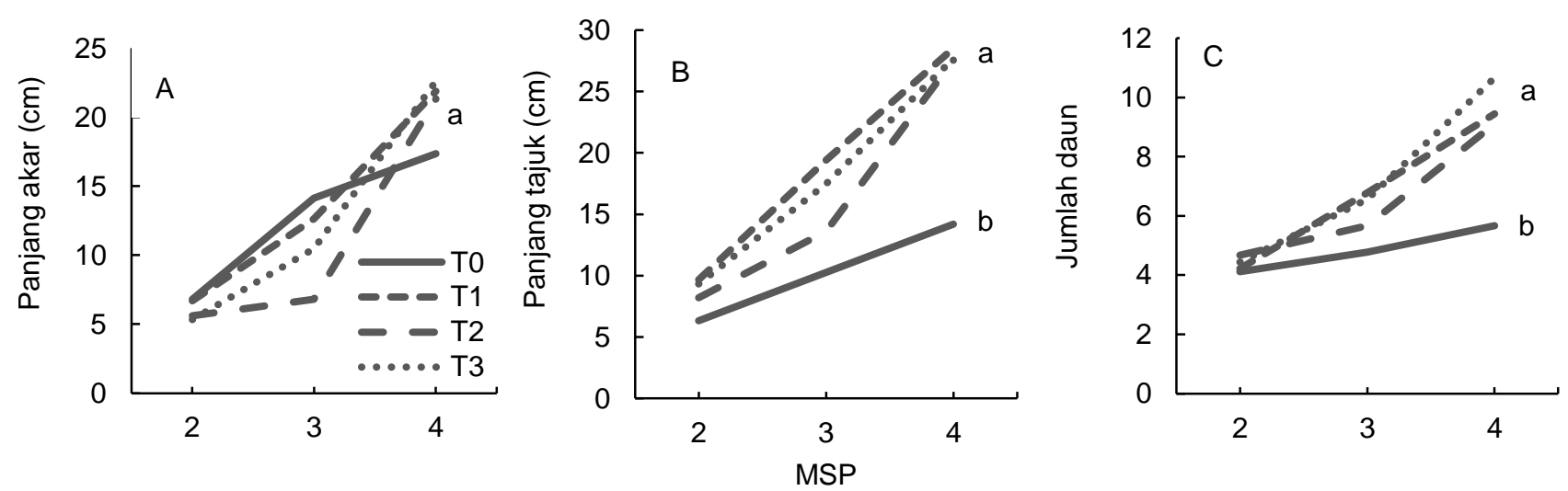

Gambar 2 Panjang akar, panjang tajuk, dan jumlah daun tanaman sawi hijau pada perlakuan dosis pupuk T0, T1, T2, dan T3. Huruf yang sama di ujung garis dan di atas diagram pada masing-masing perlakuan $T$ menunjukkan perbedaan tidak nyata secara statistik pada uji BNT $(P \leq 0.05)$. 

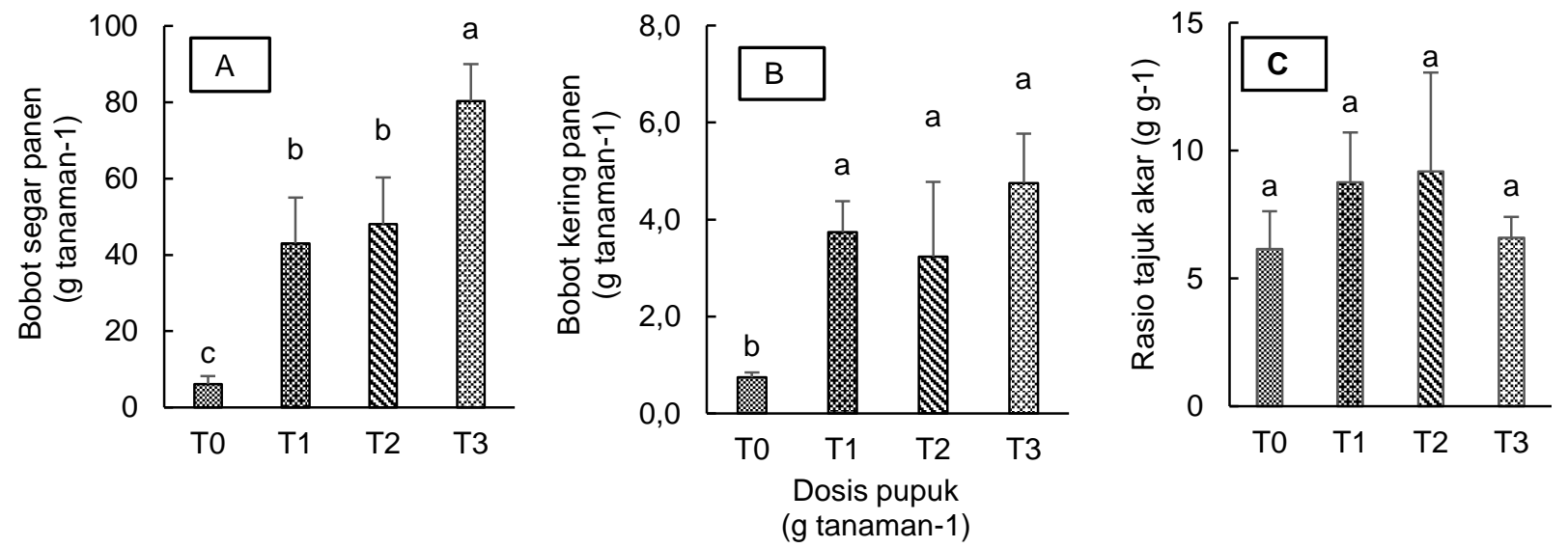

Gambar 3 Bobot segar panen (BSP), bobot kering panen (BKP), dan rasio tajuk akar (RTA) tanaman sawi hijau pada perlakuan dosis pupuk T0, T1, T2, dan T3. Huruf yang sama di atas diagram pada masing-masing perlakuan T menunjukkan perbedaan tidak nyata secara statistik pada uji BNT $(P \leq 0.05)$.

hasil BKP maupun rasio tajuk akar yang berbeda tidak nyata pada ketiga dosis tersebut. Hal ini diduga bahwa peningkatan BSP lebih dikarenakan adanya peningkatan kadar air tanaman yang berkorelasi positif dengan peningkatan dosis pupuk NPK untuk menjaga keseimbangan osmotik pada tanaman.

Pada percobaan kedua, dosis $5 \mathrm{~g}_{\text {tanaman }^{-1}}$ diaplikasikan bersamaan dengan penambahan pupuk kandang dengan kombinasi media tanam tanah, pupuk kandang, dan sekam (1:1:1/ v:v:v), sedangkan perlakuan yang diterapkan adalah berupa ukuran polibag dan waktu pemupukan dengan tujuan agar diperoleh sistem budi daya yang low input dan bersifat efektif dan efisien. Beberapa literatur menunjukkan bahwa pupuk NPK yang dikombinasikan dengan pupuk kandang memberikan hasil yang lebih tinggi (Sirappa \& Razak 2010). Hal ini menjadi dasar dilakukan percobaan kedua menggunakan dosis $5 \mathrm{~g}$ tanaman $^{-1}$ meskipun hasil yang ditunjukkan lebih tinggi pada penggunaan dosis $15 \mathrm{~g}_{\text {tanaman }}{ }^{-1}$. Penambahan komposisi pupuk kandang dan sekam dilakukan sebagai upaya untuk meningkatkan ruang udara dan bahan organik pada media tanam.

Hasil penelitian pada percobaan kedua menunjukkan bahwa sawi hijau terapung dengan perbedaan ukuran polibag menunjukkan hasil yang berbeda tidak nyata pada nilai panjang akar, panjang tajuk, jumlah daun, dan SPAD pada akhir perlakuan/panen (4 MST). Dilihat dari perbedaan ukuran polibag yang digunakan, diketahui bahwa penggunaan polibag $20 \mathrm{~cm}$ x $30 \mathrm{~cm}$ dapat menghasilkan jumlah daun tertinggi pada waktu pemupukan $2 \mathrm{~g}_{\text {tanaman }}^{-1}$ pada 1 dan 2 MST dan $1 \mathrm{~g}$ tanaman $^{-1}$ pada $3 \mathrm{MST}$, sedangkan penggunaan polibag $30 \mathrm{~cm} \times 30 \mathrm{~cm}$ dapat menghasilkan jumlah daun tertinggi pada ketiga waktu pemupukan.

Berdasarkan hasil karakter morfologi dan hasil panen yang diamati diperoleh hasil bahwa hasil panen penggunaan pupuk NPK $5 \mathrm{~g}$ tanaman $^{-1}$ pada percobaan kedua justru lebih tinggi dibanding pada dosis pupuk NPK $15 \mathrm{~g}$ tanaman $^{-1}$ pada percobaan pertama. Selain itu, nilai SPAD pun menunjukkan nilai yang cukup tinggi, yaitu berkisar $30-40$ pada 4 MST. Tambunan et al. (2013) melaporkan bahwa nilai SPAD pada kisaran 50 merupakan nilai SPAD yang cukup untuk tanaman sawi dengan umur panen 8 MST. Utami et al. (2018) juga melaporkan bahwa komposisi media tanaman (arang sekam: kompos: tanah) berpengaruh nyata pada klorofil daun, luas daun, bobot segar tanaman, dan bobot kering tanaman, sedangkan dosis NPK (4,5 g tanaman) berpengaruh nyata pada luas daun, bobot segar tanaman, dan indeks panen pada tanaman pakcoy. Pemberian pupuk kandang juga memang telah terbukti memberikan efek positif pada beberapa komoditas tanaman lainnya, seperti pada beberapa kultivar bawang (Ali et al. 2018), cabai dan kacang ercis (Jaipaul et al. 2011), serta tomat (Thakur et al. 2010).

Pada perlakuan waktu pemupukan, yaitu $5 \mathrm{~g}$ tanaman-1 pada 1 minggu setelah tanam (MST), $3 \mathrm{~g}$

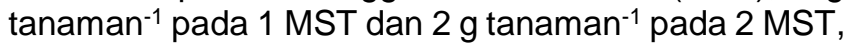
dan $2 \mathrm{~g}_{\text {tanaman }}^{-1}$ pada 1 dan 2 MST dan $1 \mathrm{~g}$ tanaman1 pada 3 MST menunjukkan hasil yang tidak berbeda nyata pada nilai panjang akar, tajuk, jumlah daun, dan hasil panen pada 4 MST, dan nilai SPAD pada 3 MST, namun ketiganya berbeda nyata dibandingkan dengan tanpa pemupukan (Tabel 1). Split waktu pemupukan sendiri bertujuan untuk mengurangi kehilangan unsur hara melalui pencucian (leaching) (Kim et al. 2015) ataupun penguapan (volatilisasi) (Adiningsih 2008). Pupuk NPK pada percobaan kedua menunjukkan bereaksi cepat karena mudah diserap oleh tanaman sawi sehingga split waktu pemupukan tidak berpengaruh pada pertumbuhan tanaman. Hal ini diduga karena pemupukan dilakukan selama masa vegetatif tanaman serta komposisi media tanam yang memiliki banyak bahan organik dengan ruang udara/air yang cukup melalui komposisi pupuk kandang dan sekam sehingga pupuk NPK dapat terserap secara langsung dalam waktu kurang lebih satu minggu setelah pemupukan. Hal ini juga didukung oleh sifat higroskopis pupuk NPK Mutiara 16:16:16 atau mudah larut dalam air sehingga cepat diserap tanaman dan 
Tabel 1 Karakter morfologi dan hasil panen tanaman sawi pada perbedaan ukuran polibag dan cara pemupukan

\begin{tabular}{|c|c|c|c|c|c|c|}
\hline \multirow[b]{2}{*}{ Perlakuan } & \multirow{2}{*}{$\begin{array}{l}\text { Panjang } \\
\text { akar }(\mathrm{cm})\end{array}$} & \multirow{2}{*}{$\begin{array}{l}\text { Panjang } \\
\text { tajuk }(\mathrm{cm})\end{array}$} & \multirow{2}{*}{$\begin{array}{l}\text { Jumlah } \\
\text { daun }\end{array}$} & \multirow[b]{2}{*}{ SPAD } & \multicolumn{2}{|c|}{ Hasil panen } \\
\hline & & & & & $\begin{array}{l}\text { Bobot segar panen } \\
\left(\mathrm{g} \mathrm{tanaman}^{-1}\right)\end{array}$ & 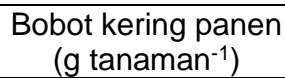 \\
\hline & & ---------2 MS & 「 ---------- & & & \\
\hline \multicolumn{7}{|l|}{ Ukuran polibag (A) } \\
\hline A1 & $9,49 \mathrm{bz}$ & $12,64^{a}$ & $5,25^{a}$ & $38,80^{a}$ & - & - \\
\hline $\mathrm{A} 2$ & $12,42^{a}$ & $12,90^{a}$ & $5,05^{a}$ & 37,54 a & - & - \\
\hline \multicolumn{7}{|l|}{$\begin{array}{l}\text { Waktu pemupukan } \\
\text { (F) }\end{array}$} \\
\hline FO & $12,94^{a}$ & $12,64^{a}$ & $5,10^{a}$ & $35,13^{c}$ & - & - \\
\hline $\mathrm{F} 1$ & $10,47^{a}$ & $12,74^{a}$ & $5,40^{a}$ & $40,80^{a}$ & - & - \\
\hline $\mathrm{F} 2$ & $10,59^{a}$ & $13,40^{a}$ & $5,20^{a}$ & $38,76^{a b}$ & - & - \\
\hline F3 & $9,80^{a}$ & 12,29 a & $4,90^{\text {a }}$ & 37,97 b & - & - \\
\hline AxF & 1,10 tn & $2,27 \mathrm{tn}$ & 0,86 tn & 0,49 tn & & \\
\hline & & - & T---------- & & & \\
\hline \multicolumn{7}{|l|}{ Ukuran polibag (A) } \\
\hline $\mathrm{A} 1$ & $29,35^{a}$ & $26,00^{a}$ & $8,75^{a}$ & $41,50^{a}$ & - & - \\
\hline$A 2$ & 30,89 a & $25,43^{a}$ & $8,65^{a}$ & $39,36^{b}$ & - & - \\
\hline \multicolumn{7}{|l|}{$\begin{array}{l}\text { Waktu pemupukan } \\
\text { (F) }\end{array}$} \\
\hline F0 & $32,00^{a}$ & $18,74^{c}$ & $6,60^{c}$ & $37,37^{b}$ & - & - \\
\hline $\mathrm{F} 1$ & 26,31 a & $26,35^{b}$ & $8,80^{b}$ & $41,67^{a}$ & - & - \\
\hline $\mathrm{F} 2$ & $30,24^{a}$ & $29,55^{\text {a }}$ & $9,90^{a}$ & $41,58^{a}$ & - & - \\
\hline F3 & $31,92^{a}$ & 28,20 ab & 9,50 ab & $41,10^{a}$ & - & - \\
\hline $\mathrm{AxF}$ & 0,37 tn & $1,44 \mathrm{tn}$ & $1,28 \mathrm{tn}$ & 0,81 tn & & \\
\hline & & $---------4 M$ & 「---------- & & & \\
\hline \multicolumn{7}{|l|}{ Ukuran Polibag (A) } \\
\hline $\mathrm{A} 1$ & $31,71^{a}$ & $34,57^{a}$ & $10,30^{a}$ & - & $88,24^{a}$ & $6,40^{a}$ \\
\hline $\mathrm{A} 2$ & 31,22 a & $32,87^{a}$ & $10,15^{a}$ & - & $90,07^{a}$ & $7,12^{a}$ \\
\hline \multicolumn{7}{|l|}{$\begin{array}{l}\text { Waktu pemupukan } \\
\text { (F) }\end{array}$} \\
\hline FO & $30,06^{a}$ & $24,13^{b}$ & $7,80^{b}$ & - & $27,76^{b}$ & $2,55^{b}$ \\
\hline $\mathrm{F} 1$ & $32,82^{a}$ & $37,01^{a}$ & $10,90^{a}$ & - & $115,74^{a}$ & $8,74^{a}$ \\
\hline $\mathrm{F} 2$ & 30,09 a & $35,54^{a}$ & $11,00^{a}$ & - & $99,00^{a}$ & $7,16^{a}$ \\
\hline F3 & $32,88^{a}$ & $38,19^{a}$ & $11,20^{a}$ & - & $114,12^{a}$ & $8,61^{a}$ \\
\hline $\mathrm{AxF}$ & 0,87 tn & $0,81 \mathrm{tn}$ & $5,21^{*}$ & & 1,72 tn & 1,78tn \\
\hline
\end{tabular}

Keterangan: ${ }^{z}$ Nilai rata-rata yang diikuti huruf yang sama pada satu kolom menunjukkan perbedaan tidak nyata secara statistik pada uji BNT $(P \leq 0,05)$. Garis $(-)$ pada tabel menunjukkan bahwa data tidak ada atau tidak dapat diperoleh.

bersifat netral (tidak mengasamkan tanah) (Azzamy 2017).

Dilihat dari hasil interaksi kedua faktor, diketahui bahwa terdapat interaksi antara ukuran polibag dan waktu pemupukan pada hasil jumlah daun di 4 MST. Interaksi kedua faktor terlihat pada penggunaan ukuran polibag $20 \mathrm{~cm}$ x $30 \mathrm{~cm}$ bersamaan dengan waktu pemupukan $3 \mathrm{~g}$ tanaman $^{-1}$ pada $1 \mathrm{MST}$ dan $2 \mathrm{~g}$ tanaman-1 pada 2 MST, ukuran polibag $20 \mathrm{~cm} \times 30 \mathrm{~cm}$ dengan waktu pemupukan $2 \mathrm{~g}_{\text {tanaman }}^{-1}$ pada 1 dan 2 MST dan $1 \mathrm{~g}$ tanaman-1 pada 3 MST, ukuran polibag $30 \mathrm{~cm}$ x $30 \mathrm{~cm}$ dengan waktu pemupukan $3 \mathrm{~g}$ tanaman 1 pada 1 MST dan $2 \mathrm{~g}$ tanaman $^{-1}$ pada $2 \mathrm{MST}$, dan ukuran polibag $30 \mathrm{~cm} \times 30 \mathrm{~cm}$ dengan waktu pemupukan $2 \mathrm{~g}$ tanaman ${ }^{-1}$ pada 1 dan 2 MST dan $1 \mathrm{~g}$ tanaman $^{-1}$ (Gambar 4). Interaksi yang dihasilkan oleh kedua faktor tersebut diduga dipengaruhi oleh faktor fisiologi tanaman dalam merespons kejenuhan air media tanam pada kedua ukuran polibag dan waktu ketersediaan unsur hara dari pupuk NPK.

Secara teknis di lapangan, penggunaan polibag $30 \mathrm{~cm}$ x $30 \mathrm{~cm}$ dinilai lebih tepat untuk digunakan pada budi daya sawi terapung, walaupun dilihat dari kadar air media tanam pada kedua polibag mencapai $80 \%$. Tanaman pada polibag $30 \mathrm{~cm}$ x $30 \mathrm{~cm}$ menunjukkan performa yang lebih stabil dan tidak mudah roboh ketika diletakkan di atas rakit, terutama pada saat kondisi hujan ataupun angin kuat, sedangkan pemupukan dapat dilakukan hanya pada saat 1 MST karena lebih efektif dan efisien. Berdasarkan hasil kedua percobaan yang telah dilakukan maka dapat direkomendasikan penggunaan polibag $30 \mathrm{~cm} \times 30 \mathrm{~cm}$ dengan dosis

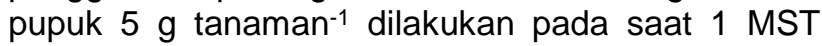
dengan kombinasi media tanam tanah, pupuk kandang, dan sekam (1:1:1/v:v:v) untuk memperoleh praktik budi daya sawi hijau yang efektif dan efisien.

\section{KESIMPULAN}

Pada budi daya sawi hijau terapung, dosis pupuk NPK $15 \mathrm{~g}^{\text {tanaman }}{ }^{-1}$ dengan komposisi media tanam yang terdiri atas tanah dan pupuk kandang (3:1/ v:v) memberikan hasil bobot segar panen tertinggi, namun penggunaan dosis NPK $5 \mathrm{~g}$ tanaman $^{-1}$ dapat 


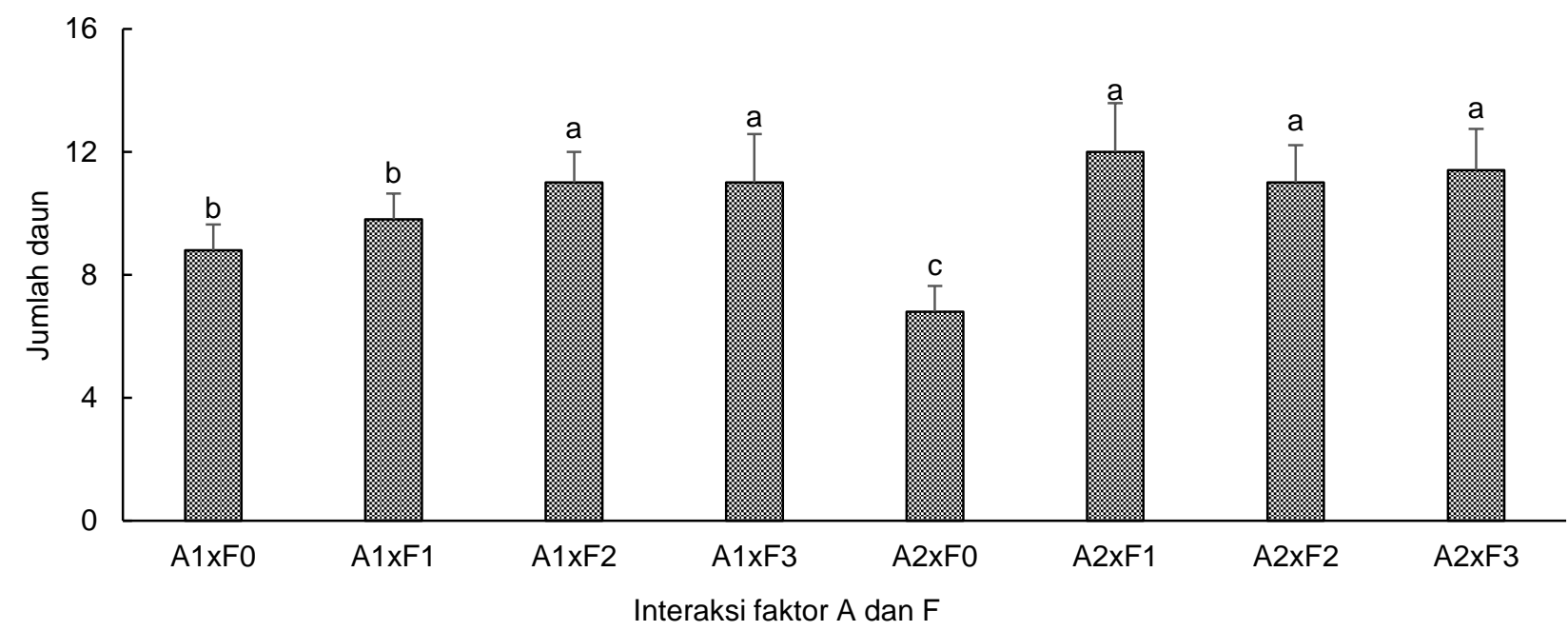

Gambar 4 Jumlah daun pada hasil interaksi faktor ukuran polibag (A) dan aplikasi pemupukan (P) pada 4 MST. Huruf yang sama di atas diagram pada masing-masing hasil interaksi menunjukkan perbedaan tidak nyata secara statistik pada uji BNT $(P \leq 0,05)$.

memberikan hasil bobot segar panen yang lebih tinggi dibandingkan dengan dosis pupuk NPK $15 \mathrm{~g}$ tanaman1 dengan komposisi media tanam berupa tanah, pupuk kandang, dan sekam padi (1:1:1/ v:v:v). Berdasarkan ukuran polibag dan waktu pemupukan diperoleh hasil yang terbaik berupa penggunaan polibag $30 \mathrm{~cm} \times 30$ $\mathrm{cm}$ dengan waktu pemupukan $1 \mathrm{MST}$. Dengan demikian, budi daya sawi hijau terapung menggunakan polibag ukuran $30 \mathrm{~cm} \times 30 \mathrm{~cm}$ dengan dosis pupuk $5 \mathrm{~g}$ tanaman $^{-1}$ pada saat $1 \mathrm{MST}$ merupakan praktik budi daya sawi hijau terapung yang efektif dan efisien.

\section{UCAPAN TERIMA KASIH}

Ucapan terima kasih disampaikan kepada Kementerian Riset Teknologi dan Pendidikan Tinggi (Ristekdikti), Program PMDSU 2016 Nomor 326/SP2H/LT/DRPM/IX/2016. Ucapan terima kasih juga disampaikan kepada pihak yang memberikan dukungan dalam penelitian atau penulisan makalah, baik sebagai mitra konsultasi.

\section{DAFTAR PUSTAKA}

Adiningsih Y. 2008. Perubahan Kandungan Nitrogen, Phospat dan Kalium pada Penyimpanan Pupuk NPK. Jurnal Riset Teknologi Industri. 2(4): 19-23. https://doi.org/10.26578/jrti.v2i4.1410

Ali M, Khan N, Khan A, Ullah R, Naeem A, Khan MW, Khan K, Farooq S, Rauf K. 2018. Organic manures effect on the bulb production of onion cultivars under semiarid condition. Pure and Applied Biology (PAB). 7(3): 1161-1170. https://doi.org/ 10.19045/bspab.2018.700135

Azzamy. 2017. Macam-Macam Jenis Pupuk NPK dan Kegunaannya. [Internet]. [diunduh pada 3 Sep
2020]. Tersedia pada: https://mitalom.com/macammacam-jenis-pupuk-npk-dan-kegunaannya/

Bernas SM, Pohan A, Fitri SNA, Kurniawan E. 2012. Model pertanian terapung dari bambu untuk budi daya kangkung darat (Ipomoea reptans Poir.) di lahan rawa. Jurnal Lahan Suboptimal. 1(2): 177185.

Daquaagrotechno. 2018. Mengenal Tanaman Sawi Hijau. [Internet]. [diunduh pada 12 Juli 2020]. Tersedia pada: http://www.daquagrotechno.org/ mengenal-tanaman-sawi-hijau/

Hervé DS, Annih, MG, Kenyi MD, Christopher, SUH. 2017. Effect of different doses of NPK fertilizer on the growth and yield of rice in Ndop, North West of Cameroon. African Journal of Agricultural Research. 12(15): 1244-1252. https://doi.org/ 10.5897/AJAR2017.12127

Irmawati, Ehara H, Suwignyo RA, Sakagami JL. 2015. Swamp rice cultivation in South Sumatra, Indonesia: an overview. Tropical Agriculture and Development. 59(1): 35-39.

Islam MA, Kamruzzaman M, Akter A, Roy PC. 2015. Perception of haor farmers about the innovative features of floating farming. International Journal of Natural and Social Sciences. 2(4): 52-58.

Jaipaul SS, Dixit AK, Sharma AK. 2011. Growth and yield of capsicum (Capsicum annum) and garden pea (Pisum sativum) as influenced by organic manures and biofertilizers. Indian Journal of Agricultural Sciences. 81(7): 637-642.

Karya B, Hawalid H, Hawayanti E. 2015. Pengaruh jenis rakit limbah botol plastik dan jenis pupuk organik padat terhadap pertumbuhan dan produksi tanaman sawi (Brassica oleracea L. var. alboglabra Bailey) di lahan rawa lebak yang tergenang. Klorofil. 10(2): 106-110. 
Lakitan B, Hadi B, Herlinda S, Siaga E, Widuri LI, Kartika K, Lindiana L, Yunindyawati Y, Meihana M. 2018. Recognizing farmers' practices and constraints for intensifying rice production at Riparian Wetlands in Indonesia. NJAS-Wageningen Journal of Life Sciences. 85: 10-20. https:// doi.org/10.1016/j.njas.2018.05.004

Marlina NS, Syafrullah. 2014. Pemanfaatan jenis kompos rumput rawa pada mentimun (Cucumis sativus L) dengan teknologi rakit terapung di lahan lebak. In Prosiding Seminar Nasional Lahan Sub Optimal. Palembang, $12^{\text {th }}$ Sep 2014. Palembang (ID).

Prasetya, ME. 2014. Pengaruh pupuk NPK mutiara dan pupuk kandang sapi terhadap pertumbuhan dan hasil tanaman cabai merah keriting varietas arimbi (Capsicum annuum L.). Agrifor. 13(2): 191-198.

Siaga E, Lakitan B, Bernas SM, Wijaya A, Lisda R, Ramadhani F, Widuri LI, Kartika K, Meihana M. 2018. Application of floating culture system in chili pepper (Capsicum annum L.) during prolonged flooding period at riparian wetland in Indonesia. Australian Journal of Crop Science. 12(5): 808-816. https://doi.org/10.21475/ajcs.18.12.05.PNE1007

Sirappa MP, Razak N. 2010. Peningkatan produktivitas jagung melalui pemberian pupuk $\mathrm{N}, \mathrm{P}, \mathrm{K}$ dan pupuk kandang pada lahan kering di Maluku. In Prosiding Pekan Serealia Nasional, 277-286. Maros 26$30^{\text {th }}$ Juli 2010. Maluku (ID).

Siregar J. 2015. Examining of several hydroponics nutrients for lettuce in modified floating system hydroponic technology. Jurnal Teknik Pertanian. 4(1): 65-75.
Syafrullah S. 2014. Sistem pertanian terapung dari limbah plastik pada budi daya bayam (Amaranthus tricolor L.) di lahan rawa lebak. Klorofil. 9(2): 80-83.

Susila AD, Koerniawati Y. 2004. Pengaruh volume dan jenis media tanam pada pertumbuhan dan hasil tanaman selada (Lactuca sativa) dalam teknologi hidroponik sistem terapung. Jurnal Agronomi Indonesia (Indonesian Journal of Agronomy). 32(3): 16-21.

Tambunan MA, Barus A, Ginting J. 2013. Respons pertumbuhan dan produksi sawi (Brassica juncea L.) terhadap interval penyiraman dan konsentrasi larutan pupuk Npk secara hidroponik. Jurnal Agroekoteknologi Universitas Sumatera Utara. 1(3). 864-872

Thakur KS, Kumar D, Vikram A, Thakur AK, Mehta DK. 2010. Effect of organic manures and biofertilizers on growth and yield of tomato and French bean under mid hills of Himachal Pradesh. Journal of Hill Agriculture. 1(2): 176-178.

Utami S, Tarigan DM, Syair IF. 2020. Response of Growth Mustard Plant Pakchoy (Brassica Chinensis L.) the Composition of Plant Medium and Dosage of Npk by Verticulture. In Proceeding International Conference Sustainable Agriculture and Natural Resources Management (ICoSAaNRM 2018). 2(1):129-134. Medan, August 28-29, 2018. Medan (ID).

Utomo WY, Bayu ES, Nuriadi I. 2014. Keragaan beberapa varietas pak choi (Brassica rapa L. ssp. chinensis (L.) pada dua jenis larutan hara dengan metode hidroponik terapung. Jurnal Online Agroteknologi. 2(4): 1661-1666. 